\title{
Increased expression of NLRP3 inflammasome in placentas from pregnant women with severe preeclampsia
}

\author{
Ingrid C.Weel ${ }^{\mathrm{a}}$, Mariana Romão-Veiga ${ }^{\mathrm{a}}$, Mariana L. Matias ${ }^{\mathrm{b}}$, Eduardo G. Fioratti ${ }^{\mathrm{a}}$, \\ Jose C. Peraçoli ${ }^{\mathrm{b}}$, Vera T. Borges ${ }^{\mathrm{b}}$, João P. Araujo $\mathrm{Jr}^{\mathrm{a}}$, Maria T. Peraçoli ${ }^{\mathrm{a}, *}$ \\ a Department of Microbiology and Immunology, Institute of Biosciences, São Paulo State University, 18618-970, Botucatu, São Paulo, Brazil \\ ${ }^{\mathrm{b}}$ Department of Gynaecology and Obstetrics, Botucatu Medical School, São Paulo State University, 18618-970, Botucatu, São Paulo, Brazil
}

\section{A R T I C L E I N F O}

\section{Keywords:}

Cytokines

Immunohistochemistry

Inflammasome

Placenta

RT-qPCR

\begin{abstract}
A B S T R A C T
Preeclampsia is a pregnancy disorder characterized by imbalance between pro- and anti-inflammatory cytokines associated with high plasma levels of uric acid and Interleukin-1 beta (IL-1ß). The inflammasome is a protein complex that mediates innate immune responses via caspase- 1 activation promoting secretion of IL-1 $\beta$ and IL-18 in their active forms, and also release of the high-mobility group box 1 protein (HMGB1). As the placenta seems to play an important role in the pathogenesis of PE, the present study investigated the expression of genes and proteins related to the inflammasome in placentas from pregnant women with severe preeclampsia. Placental tissue was collected from 20 normotensive pregnant women and 20 preeclamptic women, and inflammasome components, NLRP3 (NOD-like receptor family, pyrin domain-containing protein 3), caspase-1, IL-1 $\beta$ and IL-18, as well as tumor necrosis factor-alpha (TNF- $\alpha$ ) and HMGB1 were evaluated by immunohistochemistry, enzymelinked immunosorbent assay (ELISA) and also quantified by reverse transcription-qPCR (RT-qPCR). Compared with normotensive pregnant women, placenta from women with PE showed a significant increase in NLRP3, caspase-1, IL-1 $\beta$, TNF- $\alpha$ and HMGB1 mRNA. Immunohistochemical staining of NLRP3, caspase-1, IL-1 $\beta$ and TNF- $\alpha$ in placental villi, as well as the levels of caspase-1, IL-1 $\beta$, TNF- $\alpha$ and HMGB1 in placental homogenate were significantly higher in the preeclamptic group than in the normotensive group. However, mRNA expression of IL-18 and its protein concentrations were lower in placentas from preeclamptic women. The results suggest that placentas from pregnant women with preeclampsia show higher expression of NLRP3 inflammasome, which may be involved in the exaggerated inflammatory state in preeclampsia.
\end{abstract}

\section{Introduction}

Preeclampsia (PE) is an important cause of perinatal morbidity and mortality that affects between $2 \%$ and $8 \%$ of pregnancies (Duley, 2003; Kane et al., 2014) and is responsible for high maternal mortality in developing countries (Ghulmiyyah and Sibai, 2012). It is a multisystemic disorder with

a clinical diagnosis based on the development of hypertension (BP $\geq 140 \times 90 \mathrm{mmHg}$ ) and proteinuria ( $\geq 300 \mathrm{mg} / 24 \mathrm{~h}$ ) that occurs from the 20th week of pregnancy on (NHBPEP, 2000; De Oliveira et al., 2010). Although the etiology of PE is not well understood, it is thought to be primarily associated with poor placentation, excessive maternal systemic inflammation and endothelial dysfunction (Redman and Sargent, 2009; Cheng and Sharma, 2016).

Abnormal placentation is considered to be the primary cause of placental hypoxia/ischemia, which leads to the release of numerous factors into the maternal circulation generating oxidative stress, a local inflammatory response and anti-angiogenic factor production. These products activate several pathways that contribute to clinical manifestations and disease progression (George and Granger, 2011; Warrington et al., 2013). Thus, the placenta seems to play a fundamental role in the development of PE.

In preeclamptic patients, excessive production of proinflammatory cytokines (Luppi and Deloia, 2006; Peraçoli et al., 2007; Raghupathy, 2013), deficient production of the regulatory cytokine Interleukin-10 (IL-10) in the placenta (Makris et al., 2006; Weel et al., 2016) and lower concentrations of IL-10 in the circulation or produced endogenously by monocytes from peripheral blood (Peraçoli et al., 2013; Cristofalo et al.,2013) have been reported. Also, a strong association between plasma levels of uric acid and IL- $1 \beta$ has been reported in severe cases of PE (Peraçoli et al., 2013), suggesting that high levels of uric acid in the plasma of patients with PE may be related to the pathogenesis of PE by

\footnotetext{
* Corresponding author at: Department of Microbiology and Immunology, Institute of Biosciences, UNESP - Sao Paulo State University, Botucatu, Sao Paulo, CEP 18618-970, Brazil.

E-mail address: peracoli@ibb.unesp.br (M.T. Peraçoli).
} 
promoting the inflammatory response (Bainbridge and Roberts, 2008). Furthermore, Mulla et al. (2011) demonstrated that uric acid acts as a danger-associated molecular pattern (DAMP) and activates the inflammasome in the trophoblast cells, leading to IL-1 $\beta$ secretion.

The inflammasome is a protein complex that mediates innate immune response via caspase-1 activation (Guo et al., 2015), which promotes the secretion of the pro-inflammatory cytokines IL-1 $\beta$ and IL-18, and also the release of the high-mobility group box 1 protein (HMGB1) (Schroder and Tschopp, 2010; Gross et al., 2011). The inflammasome is initially activated when the pattern-recognition receptors (PRRs), such as nucleotide oligomerization domain (NOD)-like receptors (NLRs), recognize the pathogen-associated molecular patterns (PAMPs) or endogenous products of host cells, also named danger-associated molecular patterns (DAMPs) (Guo et al., 2015). Oligomerization of nucleotide-binding domain and leucine-rich repeat pyrin domain containing protein-3 (NLRP3) inflammasomes bind to the inactive precursor form the caspase- 1 enzyme, which becomes active and cleaves pro-IL-1 $\beta$, resulting in biologically active IL-1 $\beta$ generation that is subsequently secreted into the extracellular medium (Pétrilli et al., 2007; Franchi et al., 2009).

High-mobility group box 1 protein (HMGB1) was originally described as a nuclear protein present in almost all cell types (Yang et al., 2013). When HMGB1 is released from cells into the extracellular environment following necrotic cell death, it acts as a proinflammatory mediator (Chen et al., 2016) and may contribute to the development of inflammatory responses in PE (Zhu et al., 2015). It has been suggested that HMGB1 may be involved in the pathogenesis of PE due to its higher expression in syncytiotrophoblast and in maternal serum from women with severe PE (Zhu et al., 2015).

There is scant available information on the role of inflammasomes in PE. A potential involvement of the inflammasome in PE is hypothesized as metabolites such as acid uric and reactive oxygen species (ROS) could be considered danger signals driving inflammation (Khan and Hay, 2015). In a recent study, we demonstrated that mRNA expression of NLRP3, caspase- 1 , IL- $1 \beta$ and TNF- $\alpha$ by monocytes stimulated or unstimulated with monosodium urate (MSU) was significantly higher in preeclamptic women than in normotensive pregnant women. Also, monocytes from women with PE produced higher endogenous levels of IL-1 $\beta$ and TNF- $\alpha$ compared with the normotensive group, suggesting that uric acid plays a role in NLRP3 inflammasome activation contributing to the pathogenesis of PE (Matias et al., 2015).

Considering that the placenta seems to play an important role in the pathogenesis of PE, this study intended to investigate if there is activation of the inflammasome in the placentas of pregnant women with PE by evaluating gene and protein expression of NLRP3, caspase-1, IL$1 \beta$ and IL-18, as well as TNF- $\alpha$ and HMGB 1 in placental tissue.

\section{Materials and methods}

\subsection{Subjects}

Placentas were collected from 40 women with singleton pregnancies who delivered by elective cesarean section at the Obstetric Unit of Botucatu Medical School, Botucatu, SP, Brazil between March 2013 and December 2014. Twenty placentas were obtained from normotensive (NT) healthy pregnant women (controls) without hypertension-related complications who delivered at term ( $\geq 37$ weeks gestation), and 20 placentas were collected from preeclamptic women with gestational age from 28 to 39 weeks. Placentas were collected by elective cesarean section, in the absence of delivery labor, for normotensive and preeclamptic groups. Gestational age of the groups was calculated from the last menstrual period and confirmed by early ( $<12$ weeks gestation) ultrasound examination. Preeclampsia was defined as blood pressure $\geq 140 / 90 \mathrm{mmHg}$ evaluated on two occasions $2 \mathrm{~h}$ apart after 20 weeks of gestation and proteinuria of $\geq 300 \mathrm{mg} / 24 \mathrm{~h}$ in women with no previous history of hypertension (ACOG, 2002). Proteinuria in 24-h urine was measured by the Technicon RAXT automation system, and uric acid was assessed by uric acid enzymatic Trinder (Biotrol Diagnostic, Bridgewater, NJ, USA) in the Clinical Laboratory of Botucatu Medical School, Botucatu, SP, Brazil. Diagnosis of severe PE was considered when there was the presence of the following criteria: systolic blood pressure $160 \times 110 \mathrm{mmHg}$, proteinuria $\geq 2 \mathrm{~g}$ in $24 \mathrm{~h}$-urine collection, expression of imminent eclampsia, eclampsia, HELLP syndrome or acute pulmonary edema (NHBPEP, 2000). Exclusion criteria included prioe PE, pregnant women in labor, premature rupture of membranes, illicit drug use, and preexisting medical conditions such as diabetes, chronic hypertension infectious and renal diseases. The study was approved by the Ethics Committee of the Botucatu Medical School, and written informed consent was obtained from all women involved in the study. (CAAE Protocol number 349847). For pregnant women below 18 years of age, written informed consent was obtained from their parents or guardians.

\subsection{Sample collection and preparation}

All placentas from preeclamptic and normotensive pregnant women were delivered by cesarean section, without labor and were examined macroscopically and processed within $10 \mathrm{~min}$ of delivery. The tissues were obtained by cutting a vertical plane through the full thickness including the fetal and maternal surfaces. Tissues with calcification or clots were avoided. Samples of approximately $2 \mathrm{~g}$ of placental tissue were taken and used for immunohistochemical analysis, enzyme-linked immunosorbent assay (ELISA) determination and reverse transcriptionquantitative real time polymerase chain reaction (RT-qPCR) evaluation.

\subsection{Immunohistochemical analysis of placental tissues}

Protein expression of NLRP3, caspase-1, IL-1 $\beta$, IL-18, TNF- $\alpha$ and HMGB-1 was evaluated. Placental tissues embedded in paraffin were sectioned into 4- $\mu \mathrm{m}$-thick slices and placed on histologic slides pretreated with Vectabond (Vector Laboratories Inc., Burlingame, CA, USA). Deparaffinization, rehydration and antigen recovery of the material was achieved using Trilogy buffer (Cell Marque Co, Rocklin, CA, USA) in a pressure cooker (Cell Marque) for $15 \mathrm{~min}$. Then, sections were washed with phosphate buffered saline (PBS, pH 7.2), and treated with Peroxide Block (Cell Marque) for $10 \mathrm{~min}$ to block endogenous peroxidase and washed by successive baths in distilled water and PBS. The background was blocked using Background Block (Cell Marque) for $10 \mathrm{~min}$ followed by washes in distilled water and PBS. After blocking, sections were incubated for $60 \mathrm{~min}$ at $37^{\circ} \mathrm{C}$ with antigen-specific primary anti-human antibodies. The concentrations of the antibodies were previously standardized using normal and preeclamptic placentas. The following antibodies with respective dilutions were used: rabbit polyclonal anti-NLRP3 $(1 / 250)$, anti-IL-1 $\beta(1 / 50)$, anti-caspase $1(1 / 50)$ (Novus Biologicals, Littleton, CO, USA), anti-IL-18 (1/100), anti-TNF- $\alpha$ $(1 / 60)$ and anti-HMGB-1 (1/250) (Abcam Inc., Cambridge, MA, USA) diluted in antibody diluent (Cell Marque). After incubation, sections were washed in PBS and subjected to the action of signal amplifier for rabbit antibodies (Cell Marque) for $10 \mathrm{~min}$ at $37^{\circ} \mathrm{C}$. A polymer detector for rabbit antibodies (Cell Marque) was used for detection of primary antibody with incubation for $10 \mathrm{~min}$ at $37^{\circ} \mathrm{C}$. After this step, sections were washed in PBS and incubated for $5 \mathrm{~min}$ in revealing solution containing $10 \mathrm{mg}$ diaminobenzidine (DAB), $0.2 \%$ hydrogen peroxide $\left(\mathrm{H}_{2} \mathrm{O}_{2}\right), 20 \mathrm{mM}$ Trizma base and $1 \mathrm{~N} \mathrm{HCl}$ (Sigma). Sections were counterstained with Harris hematoxylin (Cell Marque) for $20 \mathrm{~s}$, and then bathed in running water. Dehydration was performed in sequential absolute ethanol baths of $90 \%, 80 \%$ and $70 \%$ alcohol, cleared in xylene (four baths) and mounted with coverslips containing Permount (Fisher Scientific, Fair Lawn, NJ, USA). To conduct the negative control reaction, primary antibody was replaced with a rabbit serum negative control (Cell Marque) containing the immunoglobulin isotype similar to the primary antibody used. 
Table 1

Primers for NLRP3, Caspase-1, IL-1 $\beta$, IL-18, TNF- $\alpha$, HMGB1 and GAPDH.

\begin{tabular}{|c|c|c|c|}
\hline Gene & Forward primer & Reverse primer & GenBank \\
\hline NLRP3 & (2826)GAGGAAAAGGAAGGCCGACA(2845) & (2917)TGGCTGTTCACCAATCCATGA(2897) & NM_004895.4 \\
\hline Caspase1 & (1065)AGACATCCCACAATGGGCTC(1084) & (1172)TGAAAATCGAACCTTGCGGAAA(1151) & NM_033292.3 \\
\hline IL-1 $\beta$ & (544)GAGCAACAAGTGGTGTTCTCC(564) & (653)AACACGCAGGACAGGTACAG(634) & NM_000576.2 \\
\hline IL-18 & (438)ACTGTAGAGATAATGCACCCCG(459) & (517)AGTTACAGCCATACCTCTAGGC(496) & NM_001562.3 \\
\hline TNF- $\alpha$ & (325)GCTGCACTTTGGAGTGATCG(344) & (462)GGGTTTGCTACAACATGGGC(443) & NM_000594.3 \\
\hline HMGB1 & (1404)TACGAAAAGGATATTGCTGC(1423) & (1505)СТССТСТТССТTСТTTTTCTTG(1484) & NM_001313893.1 \\
\hline GAPDH & (684)CGTGGAAGGACTCATGACCA(703) & (801)GGCAGGGATGATGTTCTGGA(782) & NM_002046.4 \\
\hline
\end{tabular}

The expression of cytokines was identified in placental sections by an optical microscope (Olympus CX-31) with 10X ocular and 10, 20 and $40 \mathrm{X}$ objectives. Five random fields were photographed in every section of placenta with a $20 \mathrm{X}$ objective, and were analyzed by employing the NIH-Image $J$ software. The quantitative assessment of the positive protein staining was quantified by using Hematoxylin and 3,3'Diaminobenzidine (H DAB) vector to quantify the brown color. The hematoxylin and background staining was subtracted from the quantification and the results of the protein analyzed was obtained in pixels/ um/area.

\subsection{Preparation of placental homogenates}

To prepare placental homogenates, placental tissues were washed five times in ice-cold PBS to remove remaining blood. After this, $2 \mathrm{~g}$ of tissue was placed into a homogenate plastic tube containing $10 \mathrm{~mL}$ of ice-cold PBS and protease inhibitors (complete protease inhibitor cocktail; Sigma-Aldrich, St. Louis, MO, USA). The tissue was fully homogenized with a Powergen homogenizer (Fisher Scientific, Pittsburg, PA, USA) for $30 \mathrm{~s}$ on ice. Homogenates were centrifuged at $12,000 \mathrm{~g}$ for $20 \mathrm{~min}$ at $4{ }^{\circ} \mathrm{C}$. The supernatant was collected, filtered through a $0.22 \mu \mathrm{m}$ Millipore membrane, aliquoted and stored at $-80^{\circ} \mathrm{C}$ until required for cytokine (IL-1 $\beta$, IL-18, TNF- $\alpha$ and HMGB1) and caspase-1 determination.

\subsection{ELISA quantification}

Concentrations of caspase 1, IL-1 $\beta$, IL-18, TNF- $\alpha$ and HMGB1 in placental homogenates were determined by enzyme-linked immunosorbent assay (ELISA). Quantikine ELISA kits (R \& D Systems, Minneapolis, MN, USA) were employed for human caspase-1, IL-1 $\beta$ and TNF- $\alpha$ determination according to the manufacturer's instructions. Assay sensitivity limits were $1.24 \mathrm{pg} / \mathrm{ml}$ for caspase- $1,1.0 \mathrm{pg} / \mathrm{ml}$ for IL$1 \beta$ and $5.5 \mathrm{pg} / \mathrm{ml}$ for TNF- $\alpha$. Interleukin- 18 was evaluated by a quantitative ELISA test kit for human IL-18 (MBL-Medical \& Biological Laboratories, Nagoya, Japan) with a sensitivity of $12.5 \mathrm{pg} / \mathrm{ml}$, and HMGB1 was determined by an HMGB1 ELISA Kit (IBL Internacional Shino Test, Hamburg, Germany), with a sensitivity of $0.1 \mathrm{ng} / \mathrm{ml}$. Results were expressed as pg or $\mathrm{ng} / \mathrm{g}$ of placental tissue.

\subsection{Evaluation of the expression of transcripts related to inflammation}

The placentas from normotensive and preeclamptic women were analyzed by expression of the genes encoding the proteins NLRP3, caspase-1, IL-1 $\beta$, IL-18, TNF- $\alpha$ and HMGB-1 at the transcriptional level. Total RNA was extracted from the placentas using the Total RNA Purification Kit (Norgen Biotek Corp., Thorold, Canada) according to the manufacturer's protocol. After extraction, to ensure complete removal of genomic DNA, $1 \mu \mathrm{g}$ of total RNA was incubated with DNAse I Amp Grade (Invitrogen). The purity and relative quality of all samples of total RNA obtained were determined by fluorometry using the equipment Qubit $^{\circledR}$ Fluorometric Quantitation (Life Technologies). Subsequently, the synthesis of complementary DNA (cDNA) for performing the polymerase chain reaction coupled reverse transcription
(Reverse Transcription-coupled polymerase chain reaction - RT-PCR) was conducted with $450 \mathrm{ng}$ of total RNA in $60 \mu \mathrm{L}$ reaction using ImProm- IITM Reverse Transcription System, according to manufacturer's protocol.

The quantification of gene expression of NLRP1, NLRP3, caspase-1, IL-1 $\beta$, IL-18 and TNF- $\alpha$ was made using GoTaq ${ }^{\circ}$-qPCR Master Mix (Promega, Madison, WI, USA). The device used was 7500 Fast Real Time PCR Systems (Applied Biosystems, USA).

The variants of the targets studied were aligned in the MEGA 5.1 program and subsequently each primer was selected by the software Primer-BLAST. Primers located in exon-exon junction guarantee the purity of the reaction, namely the absence of any genomic DNA that may contaminate it. The primer sequences used in this study are in Table 1.

Each reaction was set in duplicate in a total of $20 \mu \mathrm{L}$ each, which contains $0,3 \mu \mathrm{M}$ of each primer (forward and reverse), $2 \mu \mathrm{L}$ of cDNA, $10 \mu \mathrm{L}$ of master mix and $6,8 \mu \mathrm{L}$ of nuclease-free water. Additionally, was inserted a control, also in duplicate, which was included in each reaction in order to prove that there is no contamination. The conditions for the RT-qPCR reactions were: initial denaturation at $96{ }^{\circ} \mathrm{C}$ for $2 \mathrm{~min}$ and then 40 cycles at $95^{\circ} \mathrm{C}$ for $15 \mathrm{~s}$ and $60^{\circ} \mathrm{C}$ for 60 s, followed by a melting curve. The amplification of each particular transcript was confirmed by melting curve generated profile of the end of each reaction.

Expression values of the analyzed transcripts were normalized based on the concurrent analysis of the expression of the enzyme encoding glyceraldehyde-3-phosphate dehydrogenase gene (GAPDH). The calculation of the differential expression of selected genes was carried out by the data processing method compared to a standard curve (Larionov et al., 2005). All conditions, including GAPDH for each sample and the negative control reaction (No Template Control - NTC, absence of RNA) were analyzed in duplicates. To analyze the relative expression, after the analysis of gene expression, we chose an RNA sample obtained from each group, which received the relative value of 100 . All other samples received values for that sample.

\subsection{Statistical analysis}

Statistical analyses for age, gestational age, blood pressure, proteinuria and uric acid, as well as gene expression and protein concentrations, were performed employing the Mann-Whitney $U$ nonparametric test using the Prism Statistical software 9 version 6.01 (GraphPad San Diego, Calif., USA). Differences between the groups studied were considered statistically significant when the $P$ value was $<0.05$.

\section{Results}

\subsection{Subject characteristics}

Subject characteristics of all cases enrolled in this study are shown in Table 2. Maternal age was similar in the two groups evaluated. The gestational age at delivery was significantly lower in women with PE compared with NT pregnant women. Blood pressure values, proteinuria and uric acid levels were significantly higher while placental weight 
Table 2

Clinical characteristics of the study population.

\begin{tabular}{lll}
\hline Characteristics & Preeclampsia $(\mathrm{n}=20)$ & Normotensive $(\mathrm{n}=20)$ \\
\hline $\begin{array}{l}\text { Age (years) } \\
\text { Gestational age (weeks) }\end{array}$ & $27.5(15-41)$ & $27(17-37)$ \\
$\begin{array}{l}\text { Systolic blood pressure } \\
\quad(\mathrm{mmHg})\end{array}$ & $165(140-220)^{*}$ & $39(37-40)$ \\
$\begin{array}{l}\text { Diastolic blood pressure } \\
\quad(\mathrm{mmHg})\end{array}$ & $110(95-120)^{*}$ & $80(63-80)$ \\
$\begin{array}{l}\text { Proteinuria (mg/24 h) } \\
\text { Uric acid (mg/dl) }\end{array}$ & $3120(320-22,520)^{*}$ & $<300$ \\
Placental weight $(\mathrm{g})$ & $6.6(4.3-10.1)^{*}$ & $3.9(2.2-4.7)$ \\
\hline
\end{tabular}

Results are expressed as medians and ranges.

was significantly lower in the preeclamptic group than in the NT group. All the preeclamptic women involved in the study showed severe forms of the disease, characterized by proteinuria $\geq 2 \mathrm{~g}$ in $24 \mathrm{~h}$-urine collection $(60 \%)$, blood pressure $\geq 160 \times 110 \mathrm{mmHg}$ (75\%), signals of imminent eclampsia (50\%) and eclampsia (10\%). Several patients developed association between two or more of these signals of disease severity.

3.2. Immunohistochemical analysis of NLRP3, caspase-1, $I L-1 \beta, I L-18$, TNF- $\alpha$ and HMGB1 in placental tissues

According to our analysis, NLRP3, caspase-1, IL-1 $\beta$, TNF- $\alpha$, HMGB1 and IL-18 proteins were expressed by syncytiotrophoblast, stromal cells and also by endothelial cells of the fetal capillaries as shown in Figs. 1 and 2 .

All proteins evaluated showed the same localization in the two groups studied. However, differences in terms of the immunostaining intensity were found, and were quantified using the software Image J. The intensity of NLRP3, caspase-1 and IL-1 $\beta$ expression was significantly higher in the placentas of preeclamptic patients than in placentas of the NT group (Fig. 1A-I). Fig. 2 shows that the immunostaining intensity of TNF- $\alpha$ was stronger in placental tissue of preeclamptic women than in NT pregnant women (Fig. 2A). On the other hand, the staining of IL-18 was significantly lower in placentas of preeclamptic patients compared with those of NT pregnant women (Fig. 2D), while no significant differences were detected between the groups in relation to HMGB1 protein expression (Fig. 2G,H).

\subsection{Caspase-1, IL-1 $\beta, I L-18, T N F-\alpha$ and HMGB1 detected in placental homogenate}

Proteins related to inflammasome and to inflammatory responses were detected in placental homogenate by ELISA. Concentrations of caspase-1, IL-1 $\beta$, TNF- $\alpha$ and HMGB1 were significantly higher in the preeclamptic group when compared with the NT group. However, the levels of IL-18 in placental homogenate were lower in preeclamptic patients than in the NT pregnant women (Table 3).
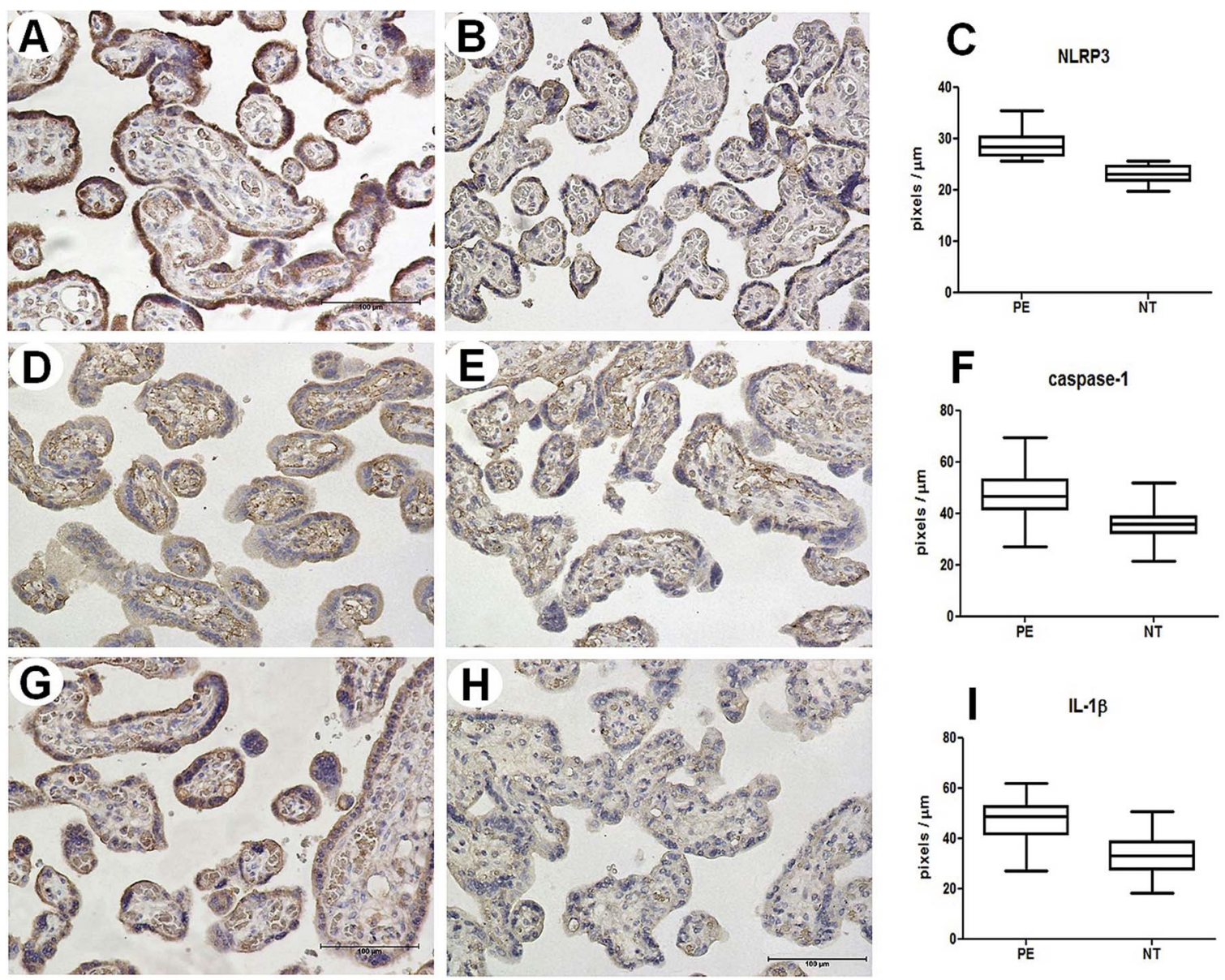

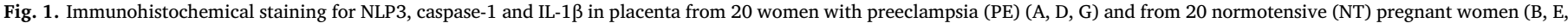
H).

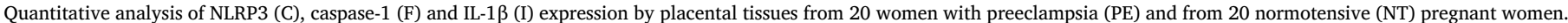

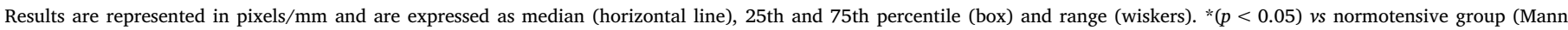
Whitney $U$ test). 

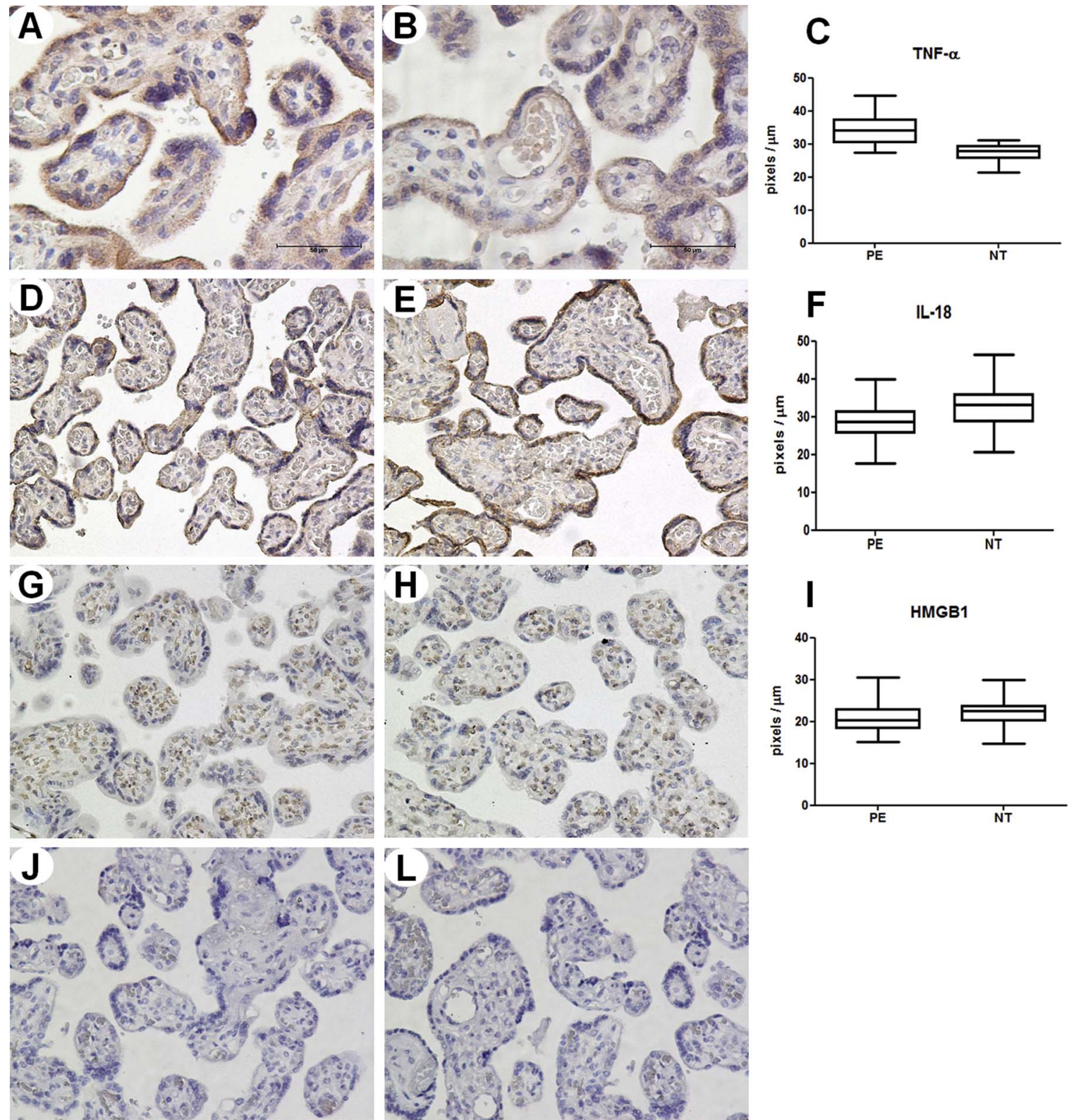

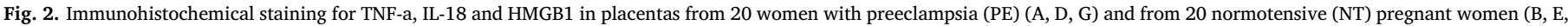
$\mathrm{H})$. No staining was observed with an isotype matched control in placental tissue from women with PE (J) and normotensive pregnant women (L).

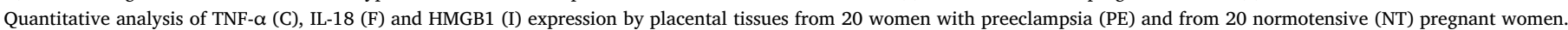

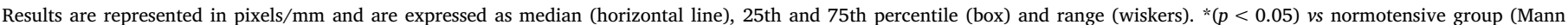
Whitney $U$ test).

Table 3

Concentrations of caspase-1, IL-1 $\beta$, IL-18, TNF- $\alpha$ and HMGB1 in placental homogenates from women with preeclampsia and from normotensive pregnant women.

\begin{tabular}{lll}
\hline Parameters & Preeclampsia $(\mathrm{n}=20)$ & Normotensive $(\mathrm{n}=20)$ \\
\hline Caspase-1 & $1536.10^{*}(873.76-2654.60)$ & $1097.50(747.67-1369.24)$ \\
IL-1 $\beta$ & $100.62^{*}(59.48-292.01)$ & $64.28(24.0-111.33)$ \\
IL-18 & $1139.20^{*}(607.06-1635.30)$ & $1538.90(436.82-1885.06)$ \\
TNF- $\alpha$ & $21.39^{*}(13.09-36.93)$ & $10.11(5.04-17.59)$ \\
HMGB1 & $18.15(10.17-45.64)$ & $10.60^{*}(8.52-20.48)$ \\
\hline
\end{tabular}

Results are expressed as medians and ranges. Data of Caspase-1, IL-1 $\beta$, IL-18 and TNF- $\alpha$ are represented in $\mathrm{pg} / \mathrm{g}$ of placental tissue, and data of HMGB1 are represented in $\mathrm{ng} / \mathrm{g}$ of placental tissue.

$*(p<0.05) v s$ normotensive group (Mann-Whitney $U$ test).

\subsection{Expression of genes related to inflammation in placental tissue}

Expression of NLRP3, caspase-1, IL-1 $\beta$, TNF- $\alpha$ and HMGB1 mRNA was significantly higher in placental tissue from pregnant women with $\mathrm{PE}$ compared with the normotensive pregnant group as shown in Fig. 3A-C, E and F respectively. On the contrary, lower gene expression of IL-18 was detected in placentas from the preeclamptic group than in those from the NT group (Fig. 3D).

\section{Discussion}

The results of the present study showed higher basal expression of NLRP3 inflammasome in placenta of the third trimester of gestation from preeclamptic women demonstrated by higher expression of mRNA for NLRP3, caspase-1 and IL-1 $\beta$, and their protein expression in placental villi detected by immunohistochemical analysis. Increased levels 

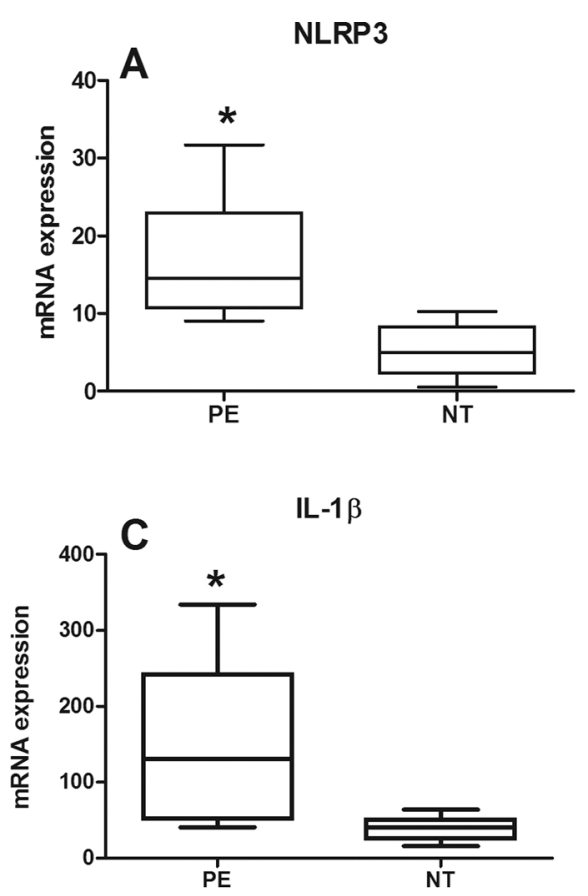

TNF- $\alpha$

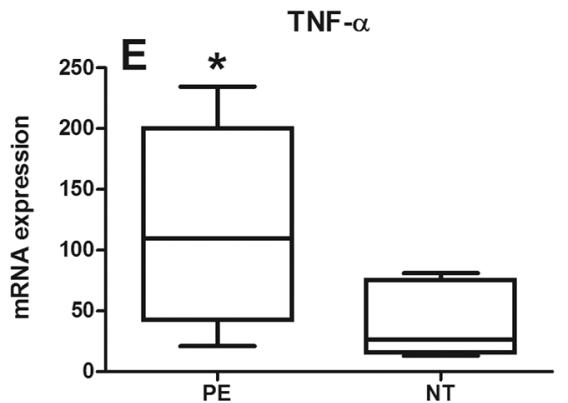

caspase-1

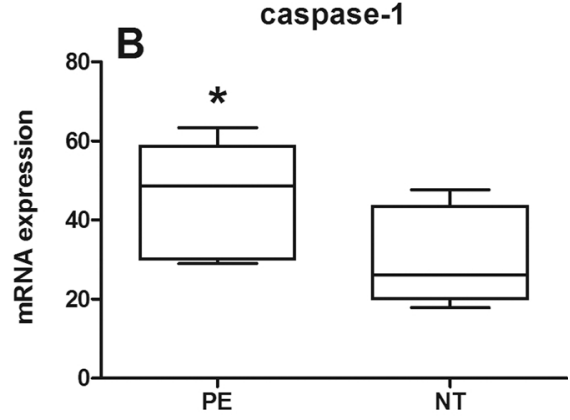

IL-18

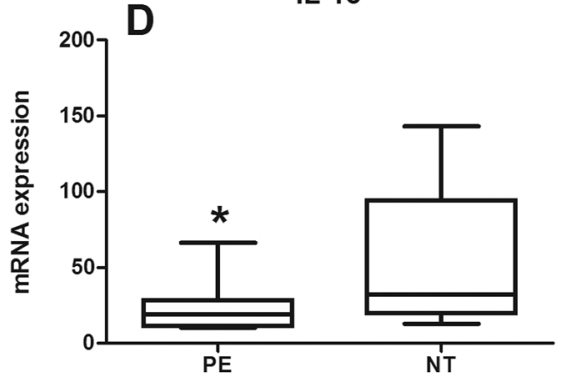

HMGB1

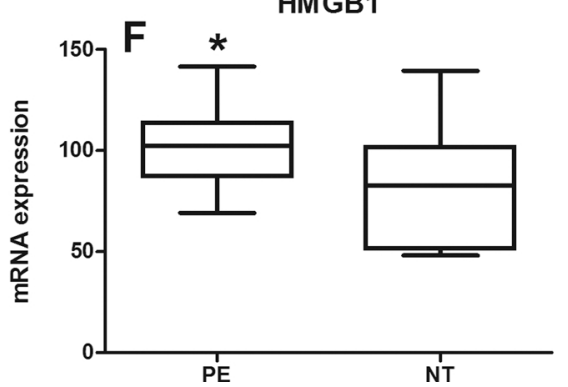

Fig. 3. Gene expression of NLRP3 (A), caspase-1 (B), IL-1 $\beta$ (C), IL-18 (D) TNF- $\alpha$ (E) and HMGB1 (F) in placental tissues from 20 women with preeclampsia (PE) and from 20 normotensive (NT) pregnant women. Results are expressed as median (horizontal line), 25th and 75th percentile (box) and range (wiskers). * $(p<0.05)$ vs normotensive group (Mann Whitney $U$ test). of caspase-1, IL-1 $\beta$, TNF- $\alpha$ and HMGB1 were also detected in the placental homogenates of women with PE relative to those of NT pregnant women.

Inflammasome studies in the placenta are scarce. To our knowledge, this is the first report on inflammasome hyperactivity in placental tissue from pregnant women with PE. The involvement of NLRP3 inflammasomes in placental immune defense was shown by Pontillo et al. (2013). Stimulation of placental cell populations, such as human first trimester cytotrophoblasts and decidual stromal cells, with lipopolysaccharide (LPS), a common gram-negative compound, led to an augmented expression of caspase-1 and IL-1 $\beta$, and the specific upregulation of NLRP3. Previous studies employing cultures of human first trimester villous trophoblasts and two trophoblast cell lines (Sw.71 and HTR-8/ SVneo) showed that monosodium urate acts as DAMP, promoting IL-1 $\beta$ secretion via NLRP3-inflammasome activation, indicative of its proinflammatory effects. Inflammasome activation in trophoblast cells could be a mechanism of inflammation induction at the maternal-fetal interface that causes adverse pregnancy outcomes, including preeclampsia (Mulla et al., 2011). Although we didn't study inflammasome in placenta of the first trimester, but from the third trimester, when PE was established, we can imply that the placental milieu resultant from syncytiotrophoblast activation by inflammatory cytokines and/or microparticles released by the injured and necrotic cells can activate the inflammasome. We have recently showed high expression of the antiangiogenic factor fms-like tyrosine-kinase-1 (Flt-1) in syncytial knots of placental villi as well as high TNF- $\alpha$ expression in syncytiotrophoblast of placenta from preeclamptic women (Weel et al., 2016). The results suggest that this anti-angiogenic factor and other inflammatory molecules, such as inflammatory cytokines, synthesized by syncytiotrophoblast may induce higher inflammasome expression in the placental tissue.

Higher expression of TNF- $\alpha$ and IL-1 $\beta$ in placental villi and increased levels of these cytokines in placental homogenates from preeclamptic women demonstrated in the present study are in accordance with previous studies suggesting that ischemia and hypoxia, resulting from the inappropriate trophoblast invasion, lead to overexpression and increased production of proinflammatory cytokines in placentas from pregnant women with PE (Hung et al., 2004; Raghupathy, 2013). An association between higher levels of TNF- $\alpha$ and NLRP3 activation was detected in peripheral blood monocytes from preeclamptic women, both stimulated and unstimulated with monosodium urate (Matias et al., 2015), suggesting the involvement of this inflammatory cytokine in inflammasome induction. A recent in vitro study demonstrated that the stimulation of a lineage of 3T3-LI mouse adipocytes with TNF- $\alpha$ induced mRNA expression of NLRP3 detected as early as one hour after stimulation, suggesting that the Nlrp3 gene is an immediate gene responsive to TNF $-\alpha$ in these cells (Furuoka et al., 2016).

The molecular mechanism involved in placental NLRP3 activation in PE is unknown. It has been proposed that the excessive or inappropriate inflammatory response observed in PE may have its origin in the placenta. A potential mechanism in PE is the shedding of syncytiotrophoblast micro-vesicles and nano-vesicles from the placenta 
into the maternal circulation exerting proinflammatory, antiendothelial and procoagulant activity in vitro, all of which are features of the maternal syndrome (Sargent et al., 2003; Chen et al., 2016). It is conceivable that these microparticles can act as DAMPs that induce hyperactive inflammasome activity resulting in the exaggerated inflammatory state in PE (Khan and Hay, 2015). DAMPs are released from injured tissues and stressed or necrotic cells, and include degraded extracellular matrix components, heat shock proteins, HMGB1 protein and nucleic acids, among others. In PE, many such DAMPs are known to contribute to both local placental inflammation and to systemic inflammation and endothelial dysfunction. As in PE syncytiotrophoblast is subjected to oxidative and inflammatory stress, inflammatory molecules such as Hsp70, HMGB1, Galectin 3 and Synctin 1 are carried by the microvesicles (Ivernsen, 2013) and may act as DAMPs both in the placenta and peripheral blood mononuclear cells in patients with PE.

HMGB1 has been shown to be involved in the pathogenesis of several inflammatory diseases by acting as a critical mediator during infection and sterile injury (Andersson and Tracey, 2011; Yang et al., 2013). The present study showed significantly higher expression of mRNA and elevated levels of HMGB1 in placental tissues from preeclamptic women compared with those from the NT group. These results are in line with other recent studies in the literature showing increased mRNA levels of HMGB1 in placentas from women with severe PE, and its higher protein levels in maternal serum (Zhu et al., 2015). Chen et al. (2016) reported that protein expression of HMGB1 was significantly increased in syncytiotrophoblast from placenta of both severe and early-onset PE compared with normotensive pregnancies.

In the present study, IL-18 mRNA and cytokine expression in placenta were significantly lower in pregnant women with PE than in the NT control group. Similar results were previously reported by Liu et al. (2011) showing decreased levels of IL-18, indoleamine 2,3-dioxigenase (IDO) and forkhead box P3 (FoxP3) mRNA in placenta from preeclamptic women compared with healthy pregnant women. According to the authors the down-regulation of IDO in PE may be partly influenced by IL-18 and result in maladaptation of maternal tolerance and is potentially a novel mechanism in the pathogenesis of PE. Furthermore, low expression of IL-18 in preeclamptic placenta might be attributed to a regulatory effect exerted by IL-18 binding protein (IL-18BP), an inhibitory molecule of IL-1 family regulatory proteins (Dinarello et al., 2013). This molecule is expressed by syncytiotrophoblast layer and is upregulated in placenta from pregnant women with PE compared to normal pregnancies, and acts as anti-inflammatory factor, suggesting that placental mechanisms are down-regulating excessive systemic inflammation in PE (Southcombe et al., 2015).

\section{Conclusion}

Together, our results demonstrated that placentas from pregnant women with severe forms of PE show higher expression of NLRP3 inflammasome, caspase-1, IL-1 $\beta$, TNF- $\alpha$ and HMGB1. These results suggest that this inflammatory complex is involved in the pathogenesis of preeclampsia. The factors involved in placental inflammasome activation and the mechanisms for its control are the subject of future studies in our laboratory.

\section{Conflicts of interest}

The authors state that they have no financial or commercial conflicts of interest.

\section{Acknowledgments}

This work was supported by the Fundação de Amparo a Pesquisa do Estado de São Paulo, FAPESP (Grant No 2012/24697-8).

\section{References}

American College of Obstetricians and Gynecologists, 2002. Diagnosis and Management of Preeclampsia and Eclampsia. ACOG Practice Bulletin No. 33 22. ACOG, Washington, DC, pp. 229-235.

Andersson, U., Tracey, K.J., 2011. HMGB1 is a therapeutic target for sterile inflammation and infection. Annu. Rev. Immunol. 29, 139-162.

Bainbridge, S.A., Roberts, J.M., 2008. Uric acid as a pathogenic factor in preeclampsia. Placenta 29, S67-S72.

Chen, Q., Yin, Y.X., Wei, J., Tong, M., Shen, F., Zhao, M., et al., 2016. Increased expression of high mobility group box 1 (HMGB1) in the cytoplasm of placental syncytiotrophoblast from preeclamptic placentae. Cytokine 85, 30-36.

Cheng, S.B., Sharma, S., 2016. Preeclampsia and health risks later in life: an immunological link. Semin. Immunopathol. 38, 699-708.

Cristofalo, R., Bannwart-Castro, C.F., Magalhães, C.G., Borges, V.T., Peraçoli, J.C., Witkin, S.S., et al., 2013.. Silibinin attenuates oxidative metabolism and cytokine production by monocytes from preeclamptic women. Free Radic. Res. 47, 268-275.

De Oliveira, L.G., Karumanchi, A., Sass, N., 2010. Preeclampsia: oxidative stress, inflammation and endothelial dysfunction. Rev. Bras. Ginecol. Obst. 32, 609-616.

Dinarello, C.A., Novick, D., Kim, S., Kaplanski, G., 2013. Interleukin-18 and IL-18 binding protein. Front. Immunol. 4, 289. http://dx.doi.org/10.3389/fimmu.2013.00289.

Duley, L., 2003. Pre-eclampsia and the hypertensive disorders of pregnancy. Br. Med. Bull. 67, 161-176.

Franchi, L., Eigenbrod, T., Muñoz-Planillo, R., Nuñez, G., 2009. The inflammasome: a caspase-1-activation platform that regulates immune responses and disease pathogenesis. Nat. Immunol. 10, 241-247.

Furuoka, M., Ozaki, K.I., Sadatomi, D., Mamiya, S., Yonezawa, T., Tanimura, S., et al., 2016. TNF- $\alpha$ induces caspase- 1 activation independently of simultaneously induced NLRP3 in 3T3-L1 cells. J. Cell. Physiol. 231, 2761-2767.

George, E.M., Granger, J.P., 2011.. Mechanisms and potential therapies for preeclampsia. Curr. Hypertens. Rep. 13, 269-275.

Ghulmiyyah, L., Sibai, B., 2012. Maternal mortality from preeclampsia/eclampsia. Semin. Perinatol. 36, 56-59.

Gross, O., Thomas, C.J., Guarda, G., Tschopp, J., 2011. The inflammasome: an integrated view. Immunol. Rev. 243, 136-151.

Guo, H., Callaway, J.B., Ting, J.P., 2015. Inflammasomes Mechanism of action, role in disease, and therapeutics. Nat. Med. 21, 677-687.

Hung, T.H., Charnock-Jones, D.S., Skepper, J.N., Burton, G.J., 2004. Secretion of tumor necrosis factor-alpha from human placental tissues induced by hypoxia-reoxygenation causes endothelial cell activation in vitro: a potential mediator of the inflammatory response in preeclampsia. Am. J. Pathol. 164, 1049-1061.

Ivernsen, A., 2013. Inflammatory mechanisms in preeclampsia. Pregnancy Hypertens. 3,58 .

Kane, S.C., Da Silva Costa, F., Brennecke, S.P., 2014. New directions in the prediction of pre-eclampsia. Aust. N.Z. J. Obstet. Gynaecol. 54, 101-107.

Khan, R.N., Hay, D.P., 2015. A clear and present danger: inflammasomes DAMPing down disorders of pregnancy. Hum. Reprod. Update 21, 388-405.

Larionov, A., Krause, A., Miller, W., 2005. A standard curve based method for relative real time PCR data processing. BMC Bioinf. 6, 62

Liu, X., Liu, Y., Ding, M., Wang, X., 2011. Reduced expression of indoleamine 2,3-dioxygenase participates in pathogenesis of preeclampsia via regulatory T cells. Mol. Med. Rep. 4, 53-58.

Luppi, P., Deloia, J.A., 2006. Monocytes of preeclamptic women spontaneously synthesize pro-inflammatory cytokines. Clin. Immunol. 118, 268-275.

Makris, A., Xu, B., Yu, B., Thornton, C., Hennessy, A., 2006. Placental deficiency of interleukin-10 (IL-10) in preeclampsia and its relationship to an IL10 promoter polymorphism. Placenta 27, 445-451.

Matias, M.L., Romão, M., Weel, I.C., Ribeiro, V.R., Nunes, P.R., Borges, V.T., et al., 2015 Endogenous and uric acid-induced activation of NLRP3 inflammasome in pregnant women with preeclampsia. PLoS One 10, e0129095.

Mulla, M.J., Myrtolli, K., Potter, J., Boeras, C., Kavathas, P.B., Sfakianaki, A.K., et al., 2011. Uric acid induces trophoblast IL-1 $\beta$ production via the inflammasome: implications for the pathogenesis of preeclampsia. Am. J. Reprod. Immunol. 2011 (65), 542-548.

National High Blood Pressure Education Program Working Group on High Blood Pressure in Pregnancy, 2000. Report of the national high blood pressure education program (NHBPEP) working group on high blood pressure in pregnancy. Am. J. Obstet. Gynecol. 183, S1-S22.

Pétrilli, V., Papin, S., Dostert, C., Mayor, A., Martinon, F., Tschopp, J., 2007. Activation of the NALP-3 inflammasome is triggered by low intracellular potassium concentration. Cell Death Diff. 14, 1583-1589.

Peraçoli, J.C., Rudge, M.V., Peraçoli, M.T., 2007. Tumor necrosis factor-alpha in gestation and puerperium of women with gestational hypertension and pre-eclampsia. Am. J. Reprod. Immunol. 57, 177-185.

Peraçoli, J.C., Bannwart-Castro, C.F., Romao, M., Weel, I.C., Ribeiro, V.R., Borges, V.T., et al., 2013. High levels of heat shock protein 70 are associated with pro-inflammatory cytokines and may differentiate early- from late-onset preeclampsia. J Reprod. Immunol. 100, 129-134.

Pontillo, A., Girardelli, M., Agostinis, C., Masat, E., Bulla, R., Crovella, S., 2013. Bacterial LPS differently modulates inflammasome gene expression and IL-1 $\beta$ secretion in trophoblast cells, decidual stromal cells, and decidual endothelial cells. Reprod. Sci. 20, 563-566.

Raghupathy, R., 2013. Cytokines as key players in the pathophysiology of preeclampsia. Med. Princ. Pract. 22, 8-19.

Redman, C.W., Sargent, I.L., 2009. Placental stress and pre-eclampsia: a revised view. 
Placenta 23, S38-S42.

Sargent, I.L., Germain, S.J., Sacks, G.P., Kumar, S., Redman, C.W., 2003. Trophoblast deportation and the maternal inflammatory response in pre-eclampsia. J. Reprod. Immunol. 59, 153-160.

Schroder, K., Tschopp, J., 2010. The inflammasomes. Cell 140, 821-832.

Southcombe, J.H., Redman, C.W., Sargent, I.L., Granne, I., 2015. Interleukin-1 family cytokines and their regulatory proteins in normal pregnancy and pre-eclampsia. Clin. Exp. Immunol. 181, 480-490.

Warrington, J.P., George, E.M., Palei, A.C., Spradley, F.T., Granger, J.P., 2013. Recent advances in the understanding of the pathophysiology of preeclampsia. Hypertension
62, 666-673.

Weel, I.C., Baergen, R.N., Romão-Veiga, M., Borges, V.T., Ribeiro, V.R., Witkin, S.S., et al., 2016. Association between placental lesions, cytokines and angiogenic factors in pregnant women with preeclampsia. PLoS One 11, e0157584. http://dx.doi.org/10. 1371/journal.pone.0157584.

Yang, H., Antoine, D.J., Andersson, U., Tracey, K.J., 2013. The many faces of HMGB1: molecular structure-functional activity in inflammation, apoptosis, and chemotaxis. J. Leukoc. Biol. 93, 865-873.

Zhu, L., Zhang, Z., Zhang, L., Shi, Y., Qi, J., Chang, A., et al., 2015. HMGB1 and RAGE signaling pathway in severe preeclampsia. Placenta 36, 1148-1152. 